\title{
Ultra-Processed Food Consumption among the Paediatric Population: An Overview and Call to Action from the European Childhood Obesity Group
}

\author{
Neha Khandpur a, b Daniela A. Neri ${ }^{a} \quad$ Carlos Monteiro ${ }^{a} \quad$ Artur Mazurc, $^{c}$ \\ Marie-Laure Frelut ${ }^{d, e} \quad$ Emma Boyland ${ }^{d, f} \quad$ Daniel Weghuber ${ }^{d, g} \quad$ David Thivel $^{d, h}$ \\ ${ }^{a}$ Department of Nutrition, School of Public Health, University of São Paulo, São Paulo, Brazil; ${ }^{b}$ Department of \\ Nutrition, Harvard T.H. Chan School of Public Health, Boston, MA, USA; ' Medical Faculty, University of Rzeszów,

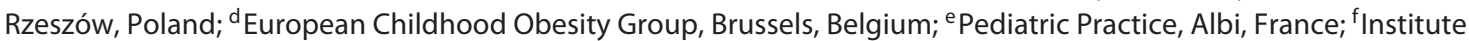 \\ of Life and Human Sciences, University of Liverpool, Liverpool, UK; 9 Department of Pediatrics, Paracelsus Medical

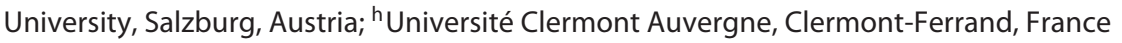

Just for a moment, think of food or beverage products that are extensively marketed, commonly consumed and widely liked by children. It is quite likely that the examples you are thinking of fall within the category of ultra-processed foods (UPF). UPF are ready-to-eat formulations of processed substances that have been extracted or refined from whole foods and that typically contain added flavours, colours, and other cosmetic additives, with little, if any, whole food remaining [1]. Soda, flavoured dairy drinks, packaged snacks, many breakfast cereals, flavoured ice creams, instant noodles and soups, nuggets and similar reconstituted meat products are all examples of UPF. These products are generally high in free sugars, saturated fat, and sodium, and low in protein, dietary fibre, micronutrients and phytochemicals, relative to their unprocessed/minimally processed counterparts $[2,3]$. They are also highly palatable, energy dense, with a high glycaemic load [4].

As the sale and consumption of these products increases worldwide [5,6], children and adolescents have the concerning distinction of being their leading consumers $[7,8]$. In the United Kingdom, $65 \%$ of calories eaten by primary and secondary school children come from UPF $[9,10]$. A

karger@karger.com

(c) 2020 S. Karger AG, Basel

www.karger.com/anm

Karger! majority of 7-year-old British children eat a diet of predominantly UPF including white bread, biscuits, fizzy drinks, crisps and chips [11]. A similarly high intake of UPF $(>55 \%)$ is seen in paediatric populations of the United States and Canada [12, 13]. Between the years 20092014 , US pre-schoolers were getting close to $60 \%$ of their daily calories from mass produced breads, cookies, savoury snacks, reconstituted meat products, milk-based drinks, breakfast cereals, juices and sodas, and frozen and ready-to-eat meals [12]. Among US school-aged children and adolescents UPF provided 66.2 and $66.4 \%$ of total daily energy respectively. Pizzas, sodas and juices were among the most consumed products among these age groups [12]. In low- and middle-income countries, the consumption of UPF is lower (18-35\%), but young children are still their earliest adopters and their largest consumers $[3,14,15]$.

There are also worrying inequalities in UPF consumption, with multi-dimensional socio-economic disadvantage being positively associated with UPF-based dietary patterns. European children whose mothers have relatively low education attainment, are younger, or have difficulty affording food are more likely to eat cheaper, less nutri- 
tious, processed food [16]. Children in low income households, with parents of migrant backgrounds who lack a social network, from single-parent families or with unemployed parents are disproportionately likely to be high UPF consumers. Besides household financial disadvantage, the presence of older siblings and being cared for at home by someone other than the mother, have also been found to predict a UPF-rich diet in children $[17,18]$.

A dietary pattern characterized by large amounts of UPF may have dire consequences for children's impressionable palates, defining lifelong consumption patterns $[19,20]$. As in adults, these products may also be central to explaining the relationship between diet and health among children. Poor rates of breastfeeding in the first hour of life, shorter than recommended or no exclusive breastfeeding, and discontinuation of breastfeeding prior to 2 years favour the incorporation of early and frequent consumption of UPF among children [21]. Some evidence also suggests that the incorporation of energy dense foods like UPFs decreases breast milk intake and may drive early cessation of breastfeeding [22, 23]. More evidence is needed to differentiate whether these decisions of substituting breast milk were the active and informed choice of the mother or a function of food industry marketing. A reliance on UPF before 2 years of age can lead to one or more forms of malnutrition. As children grow into toddlerhood, micronutrient deficiencies as well as development of overweight and obesity add to the health concerns [24]. Adolescents are especially vulnerable to undernutrition and to the double burden of malnutrition [25], which is no wonder, given that any dietary patterns based on these products is bound to be of poor nutritional quality - high in sugar, energy density, unhealthy fats and salt, and low in dietary fibre, protein, vitamins and minerals $[13,26]$. Besides nutritional deficiencies, there is some suggestion that the academic ability of children and adolescents on UPF diets may be compromised [27]. A tendency of higher consumption of added sugar (refined sugar, honey, corn syrup) and UPF was found among children with overweight, diagnosed with food addiction [28]. A high UPF intake has also been associated with an increased waist circumference [29], dyslipidaemia [30], metabolic syndrome [31], asthma and wheezing among children [32], hypertension [33], metabolic syndrome [34], myocardial infarction and stroke [35], gastrointestinal disorders, total and breast cancer [36], depression, and all-cause mortality among adults [37].

Recent research implicating UPF in the direct causation of weight gain and obesity in adults [38] is the most robust assessment of this association to date and there seems to be generally consistent evidence to suggest that these causal effects translate to the paediatric population, affecting body composition over time [39]. While the mechanisms driving these influences are yet to be fully identified, the role of the protein leverage hypothesis in partially explaining the increase in energy intake, the increase in meal eating rate, and changes in the appetite suppressing hormones and hunger hormones with a UPF diet have been acknowledged [38].

So why is it that we see such a consistent global trend in the intake of UPF among children despite all that is currently known about its negative consequences? The food environment and the nutrition transition are clearly propagating this trend $[40,41]$. However, underpinning these are the true drivers - policies and trade agreements that support and actively facilitate the penetration of transnational food corporations into the global food system and national political inertia that prevents the implementation of strong regulations around taxation, marketing restrictions and nutrition labelling. This situation has resulted in the easy penetration and access of UPF across diverse settings including within day-care centres, preschools/nurseries and schools [42-45] and perhaps even the early introduction of breast milk substitutes and UPF as complementary foods. Voluntary measures, attempts at product reformulation, self-regulation and the presence of advisory guidelines fall short of creating meaningful change. Transnational corporations have circumvented nutrition standards for school meals and the sale of competitive foods within schools in contexts like the US, with indirect endorsements or the sale of copy-cat snacks $[46,47]$ and have succeeded in rolling back standards for school lunches [48]. While some attempt has been made to restrict the marketing of these products to children via television [49-51], digital food marketing (including in social media, online gaming and on websites of interest to young people) remains largely unchartered territory [5255]. Digital UPF promotion is increasingly delivered through smart phones and tablets, resulting in an uninterrupted, immersive commercial experience [56, 57]. They are also more interactive than traditional forms of marketing (e.g., points earned on games may be traded for UPF branded merchandise); and personalizable (consumer location can be tracked via GPS, and immediate promotions based on past purchases can be encouraged when the consumer is within the vicinity of fast food restaurants). All these strategies help secure a future consumer base of brand-loyal children who are more likely to find these nutrient-poor, energy-dense UPF appealing, especially when they come emblazoned with cartoon 
Table 1. Policy and programmatic actions for the paediatric population

Policy

Developing and enforcing breast feeding guidelines

Supporting and facilitating women's choice to breast feed

Enforcing restrictions on the promotion of breast milk substitutes

Developing dietary guidelines for the paediatric population that categorically stress the avoidance of ultra-processed foods and-beverages

Regulating the sale and consumption of ultra-processed foods in and around schools

Restricting marketing of ultra-processed foods to kids

Taxation of ultra-processed foods and beverages

Front-of-pack labels for ultra-processed foods and beverages

Targeted support for the vulnerable sub-groups including socio-economically disadvantaged families

\section{Programs}

Emphasis on environmental and contextual determinants of ultra-processed food intake in programs and interventions

Community-based interventions aimed to improve parents' cooking skills and confidence

Focusing on water as the beverage of choice

Nutrition and behavior-change counselling during health screening that is based on the avoidance of ultra-processed products and in the healthy incorporation of minimally processed foods and accounts for every stage of the food decision making process from-planning to grocery shopping to cooking and eating

Nutrition education as part of the school curriculum that encourages nutrition label literacy and helps identify and avoid ultra-processed products

Research

Increasing conflict-of-interest free funding for research on paediatric health and ultra-processed food

Advancing dietary assessment methods to better distinguish and capture ultra-processed products eaten both at home and outside

Monitoring food industry practices

Surveillance of ultra-processed foods and beverage reformulation

Monitoring and evaluating policies and programmes

Uncovering the mechanisms of action of ultra-processed foods and beverages in the potential causation of various health outcomes, particularly in the paediatric population

Improving understanding of the determinants of ultra-processed foods and beverage consumption

characters, celebrities, and appealing imagery and messaging that associates these products with happiness and reward $[58,59]$.

In this current, UPF-promoting food environment, even the most motivated parent faces a challenge to ensure that their child's diet is based on nutrient-dense unprocessed/minimally processed foods, including whole grains, fruits, nuts and seeds, and vegetables, and fresh homemade meals that incorporate these ingredients. The convenience of UPF, its long shelf life and the increasing diversity in cost, type and ingredients (organic, gluten free, vegan) appeals to a wide consumer base [60]. The effects of UPF in shifting meal-time behaviours - decreasing confidence in cooking skills and lower frequencies of family meals, shortening meal times, increasing constant grazing, and reliance on ready-to-eat meals that can be consumed while indulging in some form of screentime $[10,61]$ - also detrimentally affect health by interrupting opportunities for modelling positive behaviours and strengthening social bonds within family units.

UPF and Pediatric Obesity
Indeed, it is becoming increasingly difficult to rationalize not taking a clear, universal, UPF-avoidance stance in our obesity prevention and treatment efforts, particularly as early evidence shows some promise of the focus on UPF in the prevention and treatment of paediatric obesity [62]. If the morbidity burden and the mortality and economic costs associated with the consumption of UPF are to be stymied, it is imperative we invest in a unified, global framework, which categorically stresses the avoidance of these foods and that which goes beyond leaving it to the food industry to self-police itself. This framework will also need to be flexible to account for and address contextual realities - initiatives that address the social vulnerabilities to UPF intake in one region may not be easily adaptable, or even applicable to another. Promoting the intake of minimally processed foods as the antidote may partially counteract UPF effects in countries with strong culinary traditions but other contextually relevant strategies must also be considered. Table 1 lists some possible initiatives that would meet the urgent need 
for a global framework of regulatory and unified responses to the entry, production, promotion, and sale of these products.

The European Childhood Obesity Group seeks to increase awareness among the European population of the high health, social, psychological and economic impacts of childhood obesity and, in evaluating the available scientific and clinical evidence on UPF, recognizes the importance of directly targeting the high consumption of UPF. The European Childhood Obesity Group calls for more conflict-of interest free research, the development of guidelines, and the dissemination of knowledge regarding the negative effects of UPF consumption among children and adolescents.

\section{Disclosure Statement}

The authors have no conflict of interest to declare.

\section{Funding Sources}

This work did not receive any financial support.

\section{Author Contributions}

N.K., D.A.N., C.M., and D.T. wrote the first and main draft of this paper. A.M., M.-L.F., E.B., and D.W. significantly contributed to the writing process of this paper.

\section{References}

1 Monteiro CA, Cannon G, Levy RB, Moubarac JC, Louzada ML, Rauber F, et al. Ultra-processed foods: what they are and how to identify them. Public Health Nutr. 2019 Apr; 22(5):936-41.

2 Monteiro CA, Levy RB, Claro RM, de Castro IR, Cannon G. Increasing consumption of ultra-processed foods and likely impact on human health: evidence from Brazil. Public Health Nutr. 2011 Jan;14(1):5-13.

3 Parra DC, da Costa-Louzada ML, Moubarac JC, Bertazzi-Levy R, Khandpur N, Cediel G, et al. Association between ultra-processed food consumption and the nutrient profile of the Colombian diet in 2005. Salud Publica Mex. 2019 Mar-Apr;61(2):147-54.

4 Moodie R, Stuckler D, Monteiro C, Sheron N, Neal B, Thamarangsi T, et al.; Lancet NCD Action Group. Profits and pandemics: prevention of harmful effects of tobacco, alcohol, and ultra-processed food and drink industries. Lancet. 2013 Feb;381(9867):670-9.

5 Moubarac JC. Ultra-processed food and drink products in Latin America: Trends, impact on obesity, policy implications. Washington, DC, USA: Pan American Health Organization World Health Organization; 2015. pp. 1-58.

6 Vandevijvere S, Jaacks LM, Monteiro CA, Moubarac JC, Girling-Butcher M, Lee AC, et al. Global trends in ultraprocessed food and drink product sales and their association with adult body mass index trajectories. Obes Rev. 2019 Nov;20 Suppl 2:10-19.

7 Baraldi LG, Martinez Steele E, Canella DS, Monteiro CA. Consumption of ultra-processed foods and associated sociodemographic factors in the USA between 2007 and 2012: evidence from a nationally representative cross-sectional study. BMJ Open. 2018 Mar; 8(3):e020574.

8 Moubarac JC, Batal M, Martins AP, Claro R, Levy RB, Cannon G, et al. Processed and ultra-processed food products: consumption trends in Canada from 1938 to 2011. Can J Diet Pract Res. 2014;75(1):15-21.

9 The Food Foundation. Force-fed, 2016. Available from: http://foodfoundation.org.uk/wpcontent/uploads/2016/07/The-Food-Foundation-64pp-A4-Landscape-Brochure-AWV32.pdf.

10 Martines RM, Machado PP, Neri DA, Levy RB, Rauber F. Association between watching TV whilst eating and children's consumption of ultraprocessed foods in United Kingdom. Matern Child Nutr. 2019 Oct;15(4):e12819.

11 Smith AD, Emmett PM, Newby PK, Northstone K. A comparison of dietary patterns derived by cluster and principal components analysis in a UK cohort of children. Eur J Clin Nutr. 2011 Oct;65(10):1102-9.

12 Neri D, Martinez-Steele E, Monteiro CA, Levy RB. Consumption of ultra-processed foods and its association with added sugar content in the diets of US children, NHANES 2009-2014. Pediatr Obes. 2019 Dec;14(12):e12563.

13 Moubarac JC, Batal M, Louzada ML, Martinez Steele E, Monteiro CA. Consumption of ultra-processed foods predicts diet quality in Canada. Appetite. 2017 Jan;108:512-20.

14 Marrón-Ponce JA, Sánchez-Pimienta TG, Louzada ML, Batis C. Energy contribution of NOVA food groups and sociodemographic determinants of ultra-processed food consumption in the Mexican population. Public Health Nutr. 2018 Jan;21(1):87-93.

15 Cediel G, Reyes M, da Costa Louzada ML, Martinez Steele E, Monteiro CA, Corvalán C, et al. Ultra-processed foods and added sugars in the Chilean diet (2010). Public Health Nutr. 2018 Jan;21(1):125-33.

16 Fabian Commission. A recipe for inequality, 2015. http://foodandpoverty.org.uk/wp-content/uploads/2015/03/ARecipeforInequality_WEB.pdf.

17 Camara S, de Lauzon-Guillain B, Heude B, Charles MA, Botton J, Plancoulaine S, et al.; on behalf the EDEN mother-child cohort study group. Multidimensionality of the relationship between social status and dietary patterns in early childhood: longitudinal results from the French EDEN mother-child cohort. Int J Behav Nutr Phys Act. 2015 Sep;12(1):122.

18 Wills WJ, O'Connell R. Children's and Young People's Food Practices in Contexts of Poverty and Inequality. Child Soc. 2010;32:16973.

19 Birch LL, Doub AE. Learning to eat: birth to age 2 y. Am J Clin Nutr. 2014 Mar;99(3):723S-8S.

20 Birch LL. Development of food preferences. Annu Rev Nutr. 1999;19(1):41-62.

21 Unicef Global Database. 2018, based on MICS, DHS and other nationally representative surveys 2013-2018. Available from: https://data.unicef.org/resources/dataset/infant-young-child-feeding/.

22 Islam MM, Khatun M, Peerson JM, Ahmed T, Mollah MA, Dewey KG, et al. Effects of energy density and feeding frequency of complementary foods on total daily energy intakes and consumption of breast milk by healthy breastfed Bangladeshi children. Am J Clin Nutr. 2008 Jul;88(1):84-94.

23 Islam MM, Peerson JM, Ahmed T, Dewey $\mathrm{KG}$, Brown KH. Effects of varied energy density of complementary foods on breast-milk intakes and total energy consumption by healthy, breastfed Bangladeshi children. Am J Clin Nutr. 2006 Apr;83(4):851-8.

24 The state of the word's children. Growing well in a changing world Children, food and nutrition 2019. Available from: https://www.unicef.org/media/60826/file/SOWC-2019-EAP. pdf.

25 Caleyachetty R, Thomas GN, Kengne AP, Echouffo-Tcheugui JB, Schilsky S, Khodabocus J, et al. The double burden of malnutrition among adolescents: analysis of data from the Global School-Based Student Health and Health Behavior in School-Aged Children surveys in 57 low- and middle-income countries. Am J Clin Nutr. 2018 Aug;108(2):414-24. 
26 Martínez Steele E, Popkin BM, Swinburn B, Monteiro CA. The share of ultra-processed foods and the overall nutritional quality of diets in the US: evidence from a nationally representative cross-sectional study. Popul Health Metr. 2017 Feb;15(1):6.

27 Burrows T, Goldman S, Pursey K, Lim R. Is there an association between dietary intake and academic achievement: a systematic review. J Hum Nutr Diet. 2017 Apr;30(2):11740.

28 Filgueiras AR, Pires de Almeida VB, Koch Nogueira PC, Alvares Domene SM, Eduardo da Silva C, Sesso R, et al. Exploring the consumption of ultra-processed foods and its association with food addiction in overweight children. Appetite. 2019 Apr;135:137-45.

29 Costa CS, Rauber F, Leffa PS, Sangalli CN, Campagnolo PD, Vitolo MR. Ultra-processed food consumption and its effects on anthropometric and glucose profile: A longitudinal study during childhood. Nutr Metab Cardiovasc Dis. 2019 Feb;29(2):177-84.

30 Rauber F, Campagnolo PD, Hoffman DJ, Vitolo MR. Consumption of ultra-processed food products and its effects on children's lipid profiles: a longitudinal study. Nutr Metab Cardiovasc Dis. 2015 Jan;25(1):116-22.

31 Tavares LF, Fonseca SC, Garcia Rosa ML, Yokoo EM. Relationship between ultra-processed foods and metabolic syndrome in adolescents from a Brazilian Family Doctor Program. Public Health Nutr. 2012 Jan;15(1) 82-7.

32 Melo B, Rezende L, Machado P, Gouveia N, Levy R. Associations of ultra-processed food and drink products with asthma and wheezing among Brazilian adolescents. Pediatr Allergy Immunol. 2018 Aug;29(5):504-11.

33 Mendonça RD, Lopes AC, Pimenta AM, Gea A, Martinez-Gonzalez MA, Bes-Rastrollo M. Ultra-processed food consumption and the incidence of hypertension in a Mediterranean cohort: the Seguimiento Universidad de Navarra Project. Am J Hypertens. 2017 Apr; 30(4):358-66

34 Martínez Steele E, Juul F, Neri D, Rauber F, Monteiro CA. Dietary share of ultra-processed foods and metabolic syndrome in the US adult population. Prev Med. 2019 Aug 125:40-8.

35 Srour B, Fezeu LK, Kesse-Guyot E, Allès B, Méjean C, Andrianasolo RM, et al. Ultra-processed food intake and risk of cardiovascular disease: prospective cohort study (NutriNetSanté). BMJ. 2019 May;365:11451.

36 Fiolet T, Srour B, Sellem L, Kesse-Guyot E, Allès B, Méjean C. Consumption of ultra-processed foods and cancer risk: results from $\mathrm{Nu}-$ triNet-Santé prospective cohort. BMJ. 2018 Feb;360:k322.

37 Blanco-Rojo R, Sandoval-Insausti H, LópezGarcia E, Graciani A, Ordovás JM, Banegas JR, et al. Consumption of ultra-processed foods and mortality: a national prospective cohort in Spain. Mayo Clin Proc. 2019 Nov; 94(11):2178-88.

38 Hall KD, Ayuketah A, Brychta R, Cai H, Cassimatis $\mathrm{T}$, Chen $\mathrm{KY}$, et al. Ultra-processed diets cause excess calorie intake and weight gain: an inpatient randomized controlled trial of ad libitum food intake. Cell Metab. 2019 Jul;30(1):67-77.e3.

39 Costa CS, Del-Ponte B, Assunção MC, Santos IS. Consumption of ultra-processed foods and body fat during childhood and adolescence: a systematic review. Public Health Nutr. 2018 Jan;21(1):148-59.

40 Hall KD. Did the food environment cause the obesity epidemic? Obesity (Silver Spring). 2018 Jan;26(1):11-3.

41 Popkin BM. Relationship between shifts in food system dynamics and acceleration of the global nutrition transition. Nutr Rev. 2017 Feb;75(2):73-82.

42 Champeny M, Pereira C, Sweet L, Khin M, Ndiaye Coly A, Sy Gueye NY, et al. Point-ofsale promotion of breastmilk substitutes and commercially produced complementary foods in Cambodia, Nepal, Senegal and Tanzania. Matern Child Nutr. 2016 Apr;12(Suppl 2):126-39.

43 O'Halloran SA, Lacy KE, Woods J, Grimes CA, Campbell KJ, Nowson CA. The provision of ultra-processed foods and their contribution to sodium availability in Australian long day care centres. Public Health Nutr. 2018 Jan;21(1):134-41

44 Noll PR, Noll M, de Abreu LC, Baracat EC, Silveira EA, Sorpreso IC. Ultra-processed food consumption by Brazilian adolescents in cafeterias and school meals. Sci Rep. 2019 May;9(1):7162.

45 Azeredo CM, de Rezende LF, Canella DS, Claro RM, Peres MF, Luiz OC, et al. Food environments in schools and in the immediate vicinity are associated with unhealthy food consumption among Brazilian adolescents. Prev Med. 2016 Jul;88:73-9.

46 Harris JL, Hyary M, Schwartz MB. Effects of offering look-alike products as smart snacks in schools. Child Obes. 2016 Dec;12(6):432-9.

47 Mann G. Copycat snacks: can students differentiate between school and store snacks? Appetite. 2018 Feb;121:63-8

48 Kogen. Rollback Of Nutrition Standards Not Supported By Evidence. Health Affairs Blog 2019. Available from: https://www.healthaffairs.org/do/10.1377/hblog20190312.130704/ full/.

49 Kelly B, Vandevijvere S, Ng S, Adams J, Allemandi L, Bahena-Espina L, et al. Global benchmarking of children's exposure to television advertising of unhealthy foods and beverages across 22 countries. Obes Rev. 2019 Nov;20 Suppl 2:116-28.

50 Jensen JD, Ronit K. The EU pledge for responsible marketing of food and beverages to children: implementation in food companies. Eur J Clin Nutr. 2015 Aug;69(8):896-901.
51 Raine KD, Lobstein T, Landon J, Kent MP Pellerin S, Caulfield T, et al. Restricting marketing to children: consensus on policy interventions to address obesity. J Public Health Policy. 2013 May;34(2):239-53.

52 Flowers AA, Lustyik K, Gulyás E. Virtual junk food playgrounds in Europe: advergames in the UK and Hungary. J Virtual Worlds Res. 2010;3(2).

53 Folkvord F, van 't Riet J. The persuasive effect of advergames promoting unhealthy foods among children: A meta-analysis. Appetite. 2018 Oct;129:245-51.

54 Tatlow-Golden M, Boyland E, Jewell J, Zalnieriute M, Handsley E, Breda J. Tackling food marketing to children in a digital world: transdisciplinary perspectives. Children's rights, evidence of impact, methodological challenges, regulatory options and policy implications for the WHO European Region; 2016.

55 Boyland E, Garde A, Jewell J, Tatlow-Golden $\mathrm{M}$. Evaluating implementation of the WHO set of recommendations on the marketing of foods and non-alcoholic beverages to children: Progress, challenges and guidance for next steps in the WHO European Region; 2018.

56 Bailey R, Wise K, Bolls P. How avatar customizability affects children's arousal and subjective presence during junk food-sponsored online video games. Cyberpsychol Behav. 2009 Jun;12(3):277-83.

57 Jones SC, Thom JA. Advergames play with nutrition by making fast food rewarding. 2013. Available from: https://ro.uow.edu.au/ cgi/viewcontent.cgi?referer=https://scholar. google.com.br $/$ \&httpsredir $=1 \&$ article $=2054$ \&context=sspapers.

58 Kraak VI, Story M. Influence of food companies brand mascots and entertainment companies cartoon media characters on children's diet and health: a systematic review and research needs. Obes Rev. 2015 Feb;16(2):10726.

59 Elliott C. 'Big Food'and 'gamified'products: promotion, packaging, and the promise of fun. Crit Public Health. 2015;25(3):348-60.

60 Moran AJ, Khandpur N, Polacsek M, Rimm EB. What factors influence ultra-processed food purchases and consumption in households with children? A comparison between participants and non-participants in the Supplemental Nutrition Assistance Program (SNAP). Appetite. 2019 Mar;134:1-8.

61 Avery A, Anderson C, McCullough F. Associations between children's diet quality and watching television during meal or snack consumption: A systematic review. Matern Child Nutr. 2017 Oct;13(4):e12428.

62 Poll FA, Miraglia F, D'avila HF, Reuter CP, Mello ED. Impact of intervention on nutritional status, consumption of processed foods, and quality of life of adolescents with excess weight. J Pediatr (Rio J). 2019 Aug:pii:S0021-7557(19)30152-4. 